\title{
KAJIAN PENENTUAN GETARAN SISTEM PROPULSI KAPAL PATROLI DENGAN METODE ELEMEN HINGGA
}

\author{
THE VIBRATION ANALYSIS OF PATROL BOAT \\ PROPULSION SYSTEM BY USING FINITE ELEMENT METHOD
}

\author{
Teguh Putranto ${ }^{1}$, Asjhar Imron² dan Totok Yulianto ${ }^{3}$
}

${ }^{1}$ Departemen Teknik Perkapalan, Fakultas Teknologi Kelautan Institut Teknologi Sepuluh Nopember

E-mail: theories@na.its.ac.id

\begin{abstract}
ABSTRAK
Kapal patroli adalah salah satu kapal perang berkecepatan tinggi yang digunakan untuk melakukan operasi militer dalam rangka menjaga kedaulatan wilayah maritim suatu negara. Kapal patroli tidak hanya mampu beroperasi sesuai dengan targetnya tetapi juga perlu diperhatikan juga faktor kenyamanan dan keselamatan awak kapalnya. Sebelum kapal dibangun, penentuan desain dan konstruksi kapal patroli menjadi tahap yang sangat penting karena kapal cepat sering terjadi persoalan terhadap getaran kapal yang diakibatkan sistem propulsi. Penelitian ini akan mengkaji tentang metode numerik untuk menganalisa getaran sistem propulsi kapal. Finite Element Method (FEM) merupakan salah satu metode numerik untuk menyelesaikan persamaan diferensial parsial dengan cara membagi model menjadi elemen-elemen. Pemodelan numerik dilakukan pada sistem propulsi dan sebagian dari badan kapal. Untuk memulai simulasi, kondisi batas ditentukan berdasarkan posisi sekat ceruk buritan, sekat pada strut, transom, center girder, dan side girder. Setelah simulasi selesai, frekuensi alami pada mode shape 1 - 5 didapatkan sebesar 26,26; 35,68; 44,23; 90,62; 97,66 Hz secara berurutan. Frekuensi eksitasi propeller pada kecepatan dinas didapatkan sebesar $54,93 \mathrm{~Hz}$ dimana fungsi dari rotasi propeller dan jumlah daunnya. Frekuensi 26,26 dan 35,68 Hz (mode shape 1 dan 2) mengalami getaran ke arah lateral sedangkan frekuensi 44,23 $\mathrm{Hz}$ (mode shape 3) mengalami getaran ke arah vertikal. Sistem propulsi akan beresiko mengalami resonansi pada mode shape 3 ketika beroperasi pada kecepatan 25 knot.
\end{abstract}

Kata kunci: Getaran propulsi, kapal patroli, Finite Element Method (FEM), resonansi, frekuensi.

\section{ABSTRACT}

This research discusses about the ship vibration of propulsion system by using numerical method. Finite Element Method is one of the sophisticated method to calculate the partial differential equation by dividing a model into elements. The numerical model is carried out at the propulsion system and the some part of ship. To start the simulation, the boundary condition need to be determined at the bulkhead, strut, transom, center girder, and side girder. After the simulations complete, the natural frequency at mode shape 1 - 5 can be obtained 26.26, 35.68, 44.23, 90.62, and 97.66 respectively. The excited frequency is $54.95 \mathrm{~Hz}$ which is compared with the natural frequency in order to determine the resonance condition. From the analysis, it can be concluded that the design and construction of propulsion system is closed to resonance condition in the service speed of 25 knots and the displacement will tend to vertical direction.

Keywords: Propulsi vibration, patrol boat, Finite Element Method (FEM), frequency, resonance. 


\section{PENDAHULUAN}

Getaran kapal adalah salah satu bagian dari keseluruhan masalah yang tercakup dalam dinamika kapal (ship dynamics). Secara garis besar, getaran kapal terjadi ditinjau dalam 2 hal yaitu: (1) Lenturan badan kapal akibat dari getaran yang terutama disebabkan oleh gelombang dan baling-baling, dan (2) Getaran lokal sistem konstruksi maupun komponen-komponen mesin diantaranya getaran pelat, poros, tiang mast, pompa, dan lain-lain (Imron, 1994).

Frekuensi natural dan mode shapes pada sistem propulsi didapatkan dengan cara menghitung matrik eigenvalue, yang diperoleh berdasarkan analisa dari persamaan gerak untuk getaran bebas tanpa redaman (free undamped vibration). Hasil yang didapatkan pada perhitungan yaitu frekuensi natural dan mode shape. Amplitudo vektor mode shape hanyalah dalam bentuk nilai relatif yang dapat dinormalisasi sesuai dengan prosedur yang tepat (Zhang et al., 2008).

Getaran torsional, lateral, dan aksial dianalisa pada sistem propulsi beserta mesin utamanya. Analisa dilakukan dengan menggunakan Finite Element Method (FEM) dimana poros propeller dimodelkan sebagai rotor (Tang et al., 2009). Kemudian besaran lainnya seperti berat, inersia, dan momen polar inersia dimasukkan ke dalam persamaan getaran. Bantalan poros dijadikan sebagai model pegas (Loccufier et al., 2007). Peredam getaran yang ditempatkan di titik tertentu diikutkan ke dalam analisa. Karena sistem propulsi memiliki banyak elemen yang berfungsi sebagai peredam, maka prediksi getaran yang terjadi akan mendekati kondisi yang sebenarnya (Hara et al., 1995).
Permasalahan getaran torsional pada kondisi resonansi dianalisa pada kapal katamaran. Resonansi getaran muncul disebabkan oleh frekuensi eksitasi dari balingbaling. Getaran timbul akibat baling-baling berputar dimana elemen-elemen pada sistem propulsi saling beraksi satu sama lain dan energi didesipasi melalui struktur dalam bentuk getaran (Putranto, 2017). Gaya yang menyebabkan getaran terjadi karena kontak antara komponen yang tidak seimbang, ketidaklurusan sistem perporosan, dan kerusakan batalan (Sestan et al., 2012).

Kondisi kapal akan mempengaruhi tingkat getaran yang terjadi di kapal. Getaran yang terjadi selama kapal beroperasi akan menyebabkan keausan pada bagian yang bergetar, munculnya ketidak-seimbangan pada permesinan, dan kemunduran kinerja sistem propulsi (Putranto, 2017). Apabila konstruksi pada bagian sistem propulsi diberi penguat untuk meredam getaran akibat eksitasi baling-baling, maka tingkat getaran yang dihasilkan akan mengalami penurunan (Priatmoko, 2013).

Model sistem propulsi yang akan dihitung dan dianalisa frekuensi alaminya akan dibagi menjadi elemenelemen kecil. Jumlah elemen yang terbentuk dari model sistem propulsi di penelitian ini sebanyak 235.429 elemen dengan elemen terkecil adalah $3 \times 3$ $\mathrm{mm}$ dan elemen terbesar adalah 5 × $5 \mathrm{~mm}$. Model sistem propulsi terbagi menjadi 2 bagian yaitu area part dan solid part. Area part meliputi lambung buritan dan kapal dan solid part meliputi strut, poros propeller, dan boss propeller. Penentuan elemen SOLID 185 digunakan untuk solid part dan SHELL 181 digunakan untuk area part (Han et al., 2015).

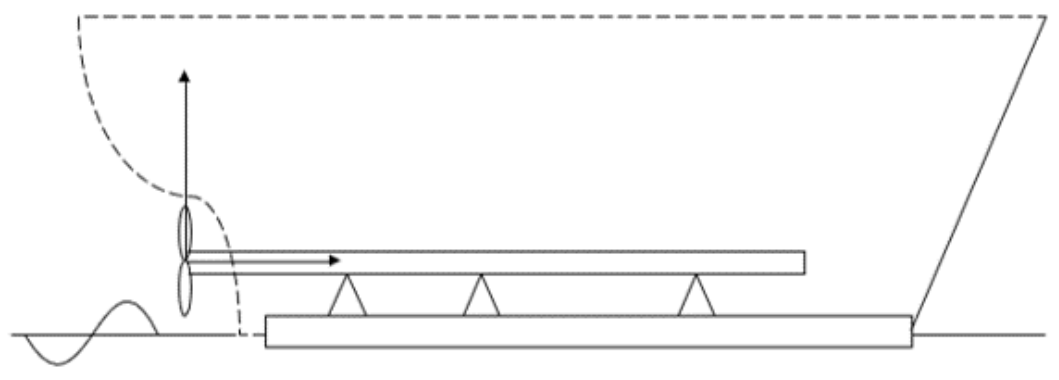

Gambar 1. Ilustrasi sistem propulsi kapal secara keseluruhan.

Figure 1. The overall of integrated coupling propulsion system. Sumber: (Tang et al., 2009)

JURNAL KELAUTAN NASIONAL, Vol. 13, No 2, Agustus 2018, Hal. 99-105 


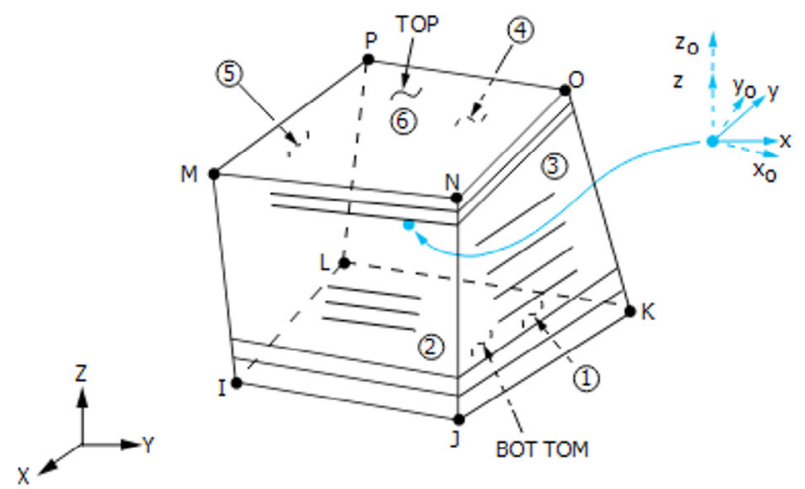

Gambar 2. Tipe elemen SOLID 185.

Figure 2. The element type of SOLID 185.

Sumber: (Han et al., 2016)

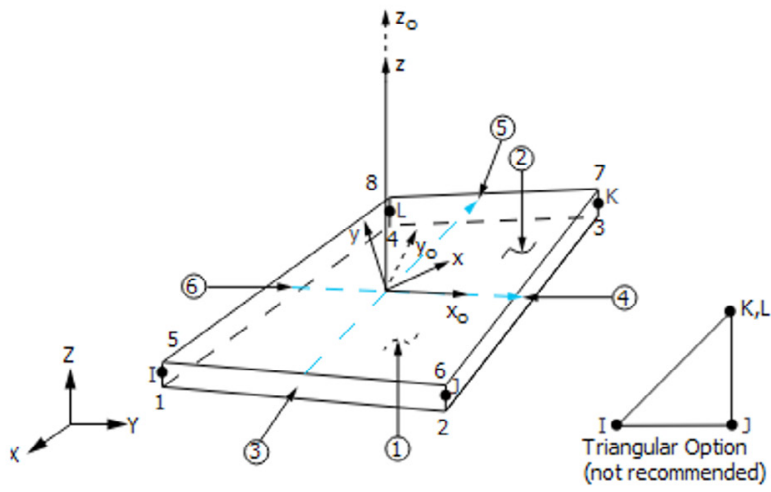

Gambar 3. Tipe elemen SHELL 181.

Figure 3. The element type of SHELL 181.

Sumber: (Tang et al., 2009)

Tipe elemen SOLID 185 digunakan untuk pemodelan 3-D untuk struktur yang solid seperti dilihat pada Gambar 2. Elemen ini didefinisikan oleh 8 (delapan) titik elemen (node) dan setiap node memiliki 3 (tiga) derajat kebebasan yaitu translasi di arah $\mathrm{x}$, y,dan $\mathrm{z}$. Elemen ini juga memiliki spesifikasi stress stiffening, large deflection, dan large strain yang cocok digunakan untuk analisa struktur khususnya getaran sistem propulsi (Han et al., 2016).
Tipe elemen SHELL 181 cocok digunakan untuk analisa struktur dengan ketebalan yang tipis seperti dilihat pada Gambar 3. Setiap elemen memiliki 4 (empat) node dengan 6 (enam) derajat kebebasan yaitu translasi dan rotasi di arah $\mathrm{x}, \mathrm{y}$, dan z. Tipe elemen ini sangat cocok digunakan untuk analisa linier, large rotation, dan large strain (Taskar et al., 2016).

Analisa frekuensi alami sistem propulsi dapat dilakukan dengan menggunakan modal analysis. Modal analysis menentukan karateristik getaran yaitu frekuensi alami dan mode shape. Mode shape adalah kecenderungan gerakan model pada setiap frekuensi (Muscia, 2018). Frekuensi alami yang didapatkan dari hasil numerik digunakan untuk mengklasifikasikan sistem propulsi apakah mengalami getaran berlebih (resonansi) atau tidak. Faktor gaya luar tidak diperlukan pada modal analysis karena nilai frekuensi natural dipengaruhi oleh massa, damping, dan kekakuan model (Huang et al., 2017). Pengaturan yang digunakan pada modal analysis hanya memberikan daerah frekuensi yang ingin diteliti. Daerah frekuensi ini akan menjadi acuan atau batasan dalam perhitungan numerik. Umumnya, daerah frekuensi yang diatur mengacu pada frekuensi eksitasi propeller (Stapersma \& Vrijdag, 2017).

\section{BAHAN DAN METODE}

Suatu sistem yang bergerak dengan amplitudo yang sama dan terjadi berulang-ulang sampai waktu yang tak hingga disebut steady state. Pada analisa sistem propulsi ini, getaran terjadi pada kondisi steady state dimana efek peredam dari getaran diabaikan. Material properties yang digunakan pada analisa sistem propulsi ini dapat dilihat pada Tabel 1.

Pemodelan analisa getaran ini meliputi: poros, boss propeller, penegar antara boss propeller dengan linggi buritan kapal (strut), bagian kapal pada daerah transom sampai ceruk buritan dan antara penumpu sisi kapal.

Tabel 1. Material properties yang digunakan untuk pemodelan Table 1. Material properties used to the modelling

\begin{tabular}{llll}
\hline Type Material & $\begin{array}{l}\text { Densitas } \\
\left(\mathbf{k g} / \mathbf{m}^{3}\right)\end{array}$ & $\begin{array}{l}\text { Modulus Young } \\
(\mathbf{G P a})\end{array}$ & \\
\hline SS316 (poros) & 8000 & 193 & 0,33 \\
BS1400AB2 (strut) & 7600 & 120 & 0,33 \\
AL2083-H116 (pelat kapal) & 2660 & 71 & 0,33 \\
AL6082-T6 (penegar T) & 2700 & 70 & 0,33 \\
AL6061-T6 (linggi) & 2700 & 68,9 & 0,33 \\
\hline
\end{tabular}


Tabel 2. Kondisi batas arah $\mathrm{x}, \mathrm{y}$, dan $\mathrm{z}$ $($ diam $=0$ dan bebas $=1)$.

Table 2. The boundary condition in $x, y, z$ directions (fixed $=0$ and free $=1$ ).

\begin{tabular}{lccc}
\hline Posisi & \multicolumn{3}{c}{ Kondisi } \\
& $\mathbf{x}$ & $\mathbf{y}$ & $\mathbf{z}$ \\
\hline Ujung depan poros & 0 & 0 & 0 \\
Sekat ceruk buritan & 0 & 0 & 0 \\
Sekat pada strut & 0 & 0 & 0 \\
Transom 1 & 0 & 1 & \\
Penumpu tengah & 1 & 1 & 0 \\
Penumpu sisi & 1 & 1 & 1 \\
\hline
\end{tabular}

pemodelan ini bertujuan untuk menganalisa getaran yang terjadi pada sistem propulsi dan mode shape yang digunakan untuk analisa kemungkinan kerusakan yang terjadi ketika sistem propulsi terjadi resonansi. Kondisi batas pemodelan sistem propulsi didapat dilihat pada Tabel 2.

Karena mesin utama kapal tidak dimodelkan pada analisa ini, maka ujung depan poros dikondisikan diam. Pada bagian transom, gerakan lateral dan vertikal dikondisikan diam. Untuk sekat baik di ceruk buritan maupun di posisi strut dikondisikan diam. Gambar 4 menunjukkan pemodelan sistem propulsi beserta bagian buritan kapal dengan penempatan kondisi batasnya.
Sistem dapat bergetar apabila sistem bertumpu pada satu titik atau lebih yang kondisinya diam. Pada analisa getaran sistem propulsi ini, kondisi batas ditentukan pada 5 bagian dari sistem propulsi. Ketika gaya dorong bekerja pada propeller yang berputar, maka kontak poros dengan strut, sekat ceruk buritan, dan ujung depan poros yang berhubungan dengan mesin utama akan menerima gaya reaksi ke arah depan kapal.

Kondisi batas merupakan hal yang sangat penting dalam perhitungan getaran kapal. Frekuensi alami sistem propulsi kapal akan sangat jauh berbeda ketika penerapan kondisi batas tidak sesuai dengan kondisi sebenarnya. Sistem propulsi yang semakin kaku, nilai frekuensi alami akan semakin tinggi karena kemampuan sistem propulsi untuk berosilasi akan semakin terbatas. Umumnya, frekuensi alami yang tinggi tentunya dibutuhkan konstruksi yang kompleks dan berat sehingga jika tidak dihitung secara numerik maka penambahan konstruksi akan tidak efisien. Oleh karena itu, penentuan penguat untuk sistem propulsi kapal harus mampu mengatasi dan menghindari efek getaran berlebih yang mengakibatkan resonansi.

Frekuensi natural merupakan fungsi dari kekakuan dan massa dari struktur (Tang, 2009). Kekakuan struktur bergantung pada konstruksi dari model dimana modulus elastisitas dan angka poisson akan mempengaruhi sifat elsatis dari model yang bergetar. Massa struktur bergantung pada massa jenis/densitas dari material yang dipakai pada model. Karena konstanta peredam

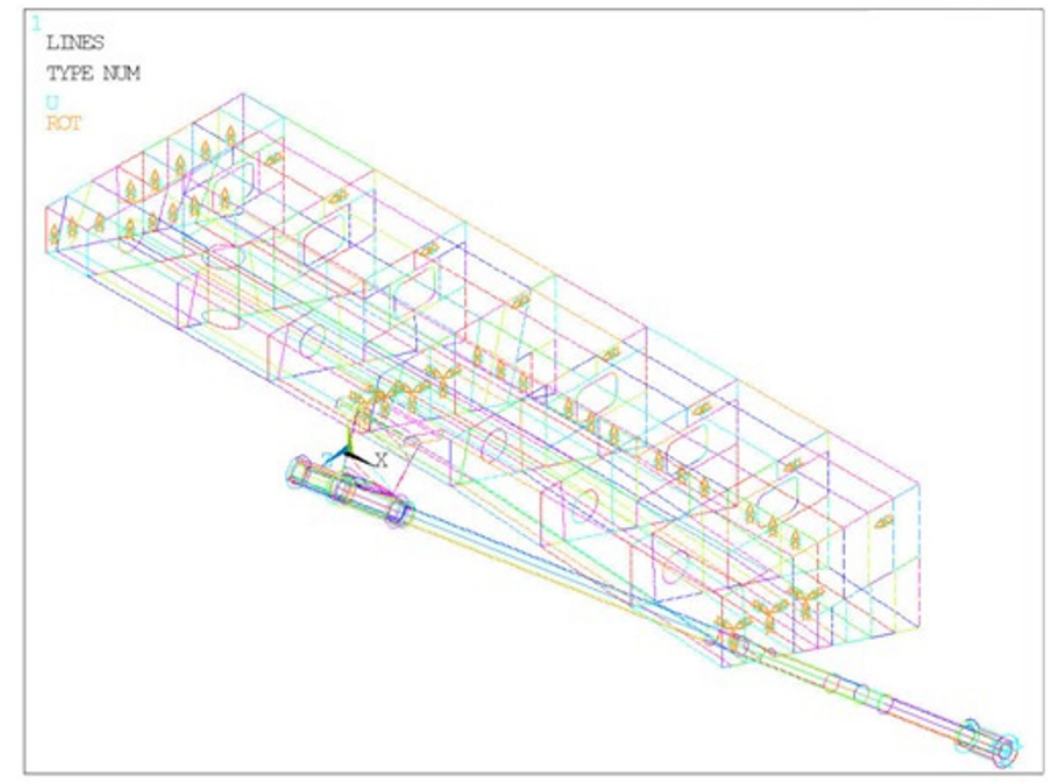

Gambar 4. Pemodelan numerik sistem propulsi kapal patroli.

Figure 4. The numerical model of patrol poat propulsion system. Sumber: Hasil pemodelan

JURNAL KELAUTAN NASIONAL, Vol. 13, No 2, Agustus 2018, Hal. 99-105 
pada perhitungan frekuensi natural ini diabaikan, maka sistem akan bergetar dengan kondisi steady state.

Ketika propeller mulai berputar, frekuensi eksitasi propeller ( $\mathrm{f}$ ) akan mulai muncul. Besar frekuensi eksitasi propeller dipengaruhi oleh putaran propeller (RPM) dan jumlah daunnya (Z) dimana dirumuskan pada Persamaan 1.

$$
f=\frac{R P M}{60} z
$$

Getaran kapal identik dengan gerakan osilasi harmonik beraturan dimana persamaannya dapat dituliskan dan diselesaikan secara analitik. Untuk kasus sistem propulsi sederhana yang melibatkan poros propeller saja, metode analitik mampu untuk menyelesaikan persamaan getaran. Namun untuk kasus sistem propulsi yang kompleks yang meliputi tidak hanya model poros propeller saja tetapi juga stern tube, bantalan poros dan perlengkapan propulsi lainnya, metode numerik digunakan untuk menyelesaikan persamaan getaran kapal. Persamaan 2 merupakan formula getaran kapal (x) dengan variabel added mass (m), damping coefficient ( $\mathrm{c}$ ), dan restoring coefficient (k).

$$
m \ddot{x}+c \dot{x}+k x=0
$$

\section{HASIL DAN PEMBAHASAN}

Pada kecepatan dinas, putaran propeller sebesar 824 rpm dan memiliki jumlah daun 4. Sehingga besar frekuensi eksitasi propeller didapatkan sebesar 54,93 Hz. Resonansi terjadi ketika besar frekuensi eksitasi mendekati frekuensi natural sistem propulsi. Frekuensi natural sistem propulsi pada mode shape 1 - 5 dapat dilihat pada Tabel 3.

Mode shape yang didapatkan dari simulasi numerik dapat digunakan untuk menganalisa kerusakan yang mungkin terjadi ketika kondisi resonansi. Oleh karena itu, kondisi resonansi perlu dihindari selama kapal beroperasi.

Mode shape 3 menunjukkan getaran pada frekuensi natural 44,23 Hz agak mendekati frekuensi eksitasi baling-baling. Pada Gambar 5a, 5b, dan 5c menunjukkan getaran sistem propulsi pada mode shape 1, 2, dan 3. Pada mode shape 5c dapat dilihat bahwa getaran terjadi pada arah vertikal. Bagian strut akan ikut bergerak secara vertikal, sehingga pondasi antara
Tabel 2. Frekuensi alami dan mode shape Table 2. Natural frequency and mode shape

\begin{tabular}{ll}
\hline Mode Shape & Frekuensi alami $(\mathrm{Hz})$ \\
\hline 1 & 26,26 \\
2 & 35,68 \\
3 & 44,23 \\
4 & 90,62 \\
5 & 97,66 \\
\hline
\end{tabular}

strut dengan linggi buritan kapal perlu diyakinkan ketegarannya supaya tegangan yang terjadi dapat diminimalkan. Sebenarnya tegangan dapat dikurangi dengan menambah konstruksi pada bagian strut sehingga displacement ke arah vertikal dapat dikurangi.

Gambar 5a menunjukkan bahwa pada frekuensi 26,26 $\mathrm{Hz}$ bentuk getaran yang paling dominan adalah gerakan transversal. Getaran yang berlebih dapat menyebabkan displacement ke arah transversal yang besar karena penguat yang ke arah transversal tidak mendukung efek resonansi ini.

Namun, getaran pada kondisi ini hanya terjadi ketika propeller kapal berputar pada putaran rendah sehingga tidak perlu dikhawatirkan terjadi secara terus menerus saat kapal patroli beroperasi. Sedangkan kondisi resonansi pada kecepatan penuh dapat terjadi pada Gambar 5c dimana displacement dominan ke arah vertikal. Kondisi kapal kecepatan penuh perlu diperhatikan apakah terjadi resonansi atau tidak karena secara analisa numerik kapal mengalami resonansi.

Gambar 6a menunjukkan amplitudo getaran sistem propulsi pada mode shape 1. Pada frekuensi $26,26 \mathrm{~Hz}$, nilai amplitudo sekitar $1,9 \mathrm{~mm}$ yang artinya gerakan transversal sistem propulsi maksimum sebesar 1,9 $\mathrm{mm}$. Gerakan transversal yang terlalu besar dapat mengakibatkan efisiensi gaya dorong propeller berkurang karena vektor gaya dorong akan tidak selalu ke arah memanjang kapal. Karena pada frekuensi ini kapal tidak beroperasi pada kecepatan dinas maka nilai frekuensi dan amplitudonya tidak akan berpengaruh besar terhadap efisiensi gaya dorong kapal.

Pada Gambar $6 \mathrm{c}$ menunjukkan amplitudo getaran sistem propulsi pada mode shape 3 dimana berdasarkan hasil analisa antara frekuensi eksitasi dan frekuensi alami kondisi terjadinya resonansi. Amplitudo getaran terjadi sekitar $3,75 \mathrm{~mm}$ yang artinya gerakan vertikal sistem propulsi maksimum sebesar $3,75 \mathrm{~mm}$. Jika dilihat pada gerakan mode shape-nya, displacement ini tidak 


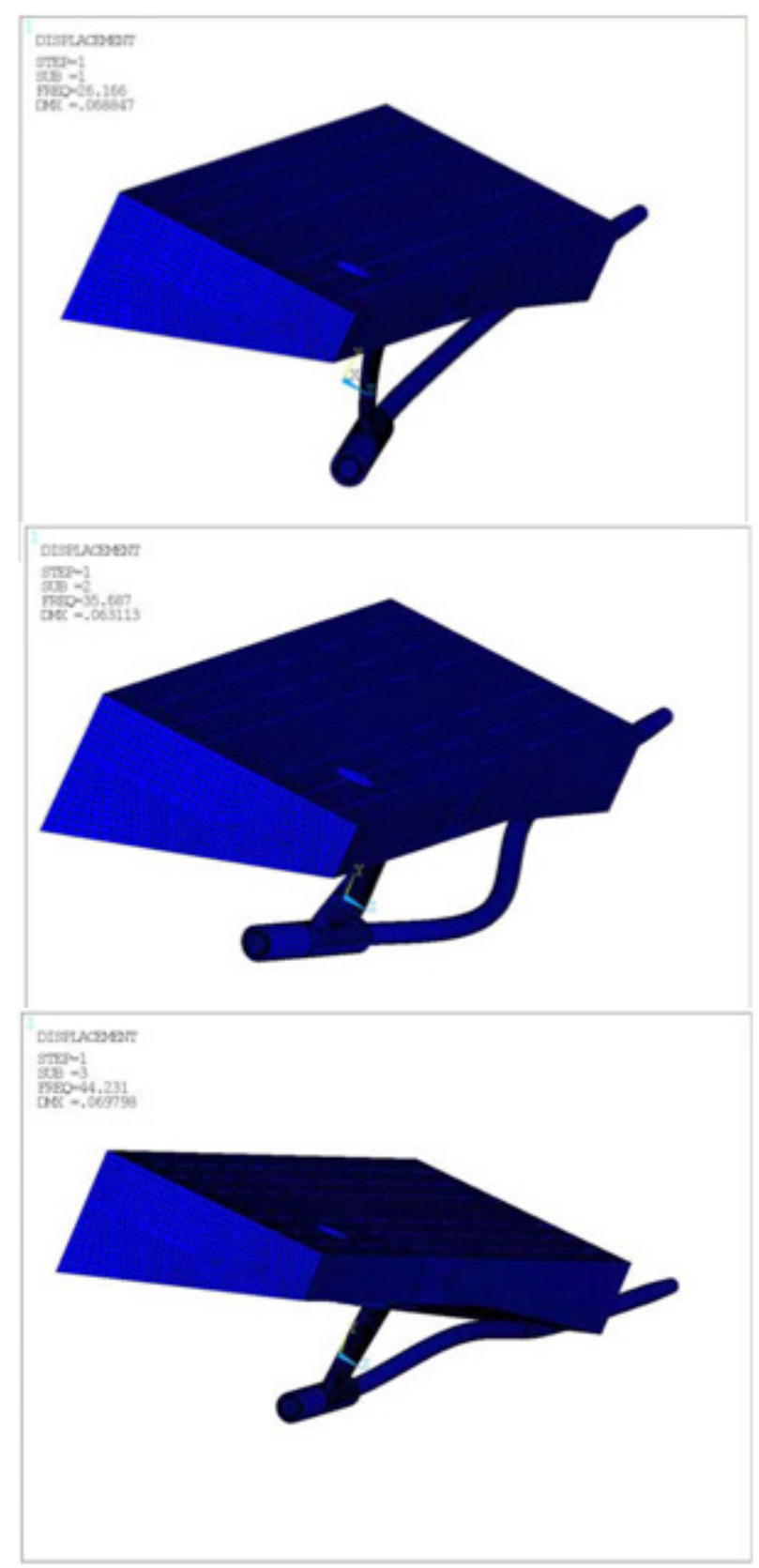

Gambar 5. Gerakan getaran pada mode shape 1, 2, dan 3. Figure 5. Vibration motion at the mode shape 1, 2, and 3. Sumber: Hasil pemodelan

akan berpengaruh besar terhadap efisiensi gaya dorong propeller karena displacement dominan terjadi pada daerah stern tube. Daerah propeller kapal ditahan oleh strut sehingga gerakan vertikalnya dapat diminimalisir. Namun, karena frekuensi ini masuk ke dalam kondisi resonansi maka perlu diperhatikan distribusi tegangan yang terjadi selama resonansi.

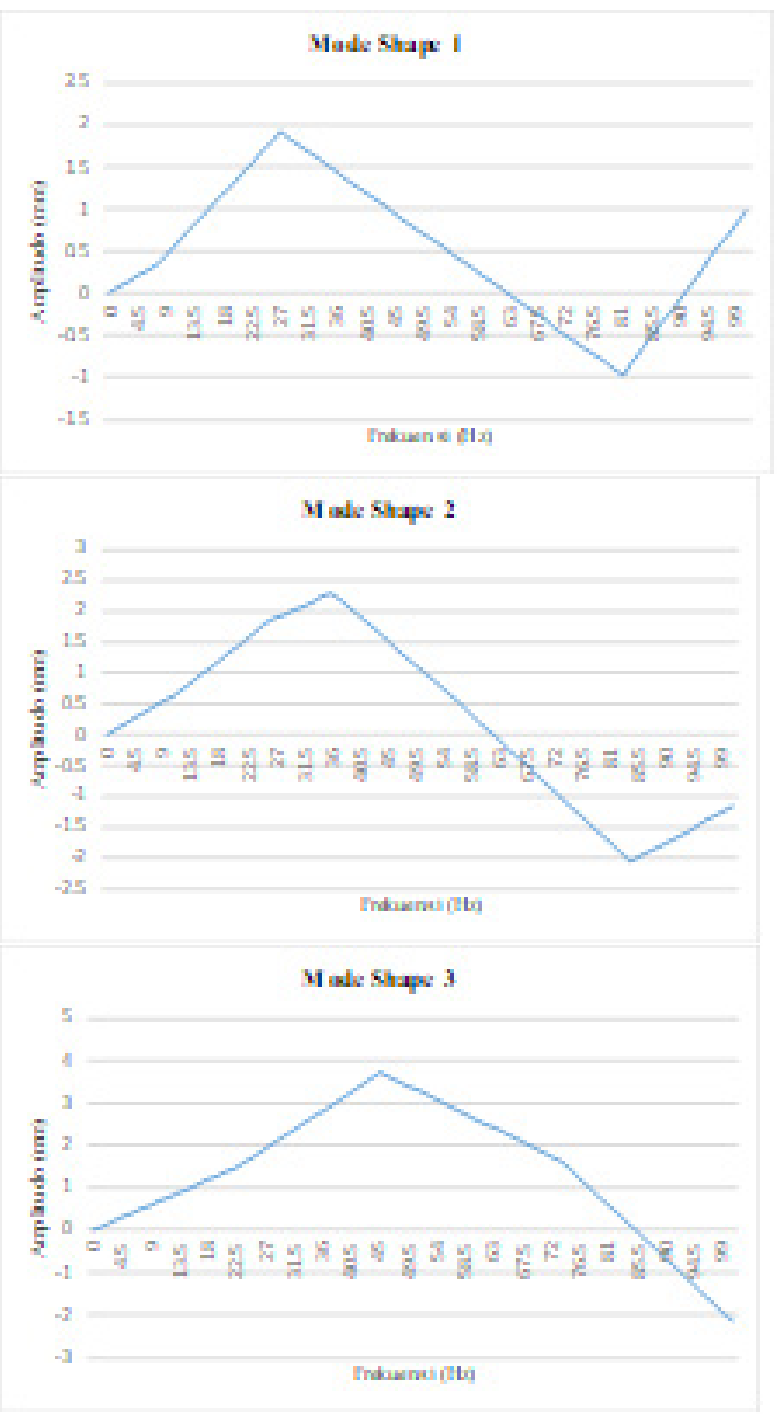

Gambar 6. Amplitudo gerakan frekuensi natural mode 1, 2, dan 3.

Figure 6. The amplitude of natural frequency in mode shape 1, 2, and 3.

Sumber: Hasil pemodelan

\section{KESIMPULAN DAN SARAN}

\section{Kesimpulan}

Dari hasil analisa getaran sistem propulsi dapat disimpulkan sebagai berikut:

1. $\quad$ Pada mode shape 1 dan 2 , getaran terjadi pada arah lateral. Pada mode shape ini, resonansi tidak akan terjadi karena frekuensi naturalnya jauh terhadap frekuensi eksitasinya

2. Ketika kapal beroperasi pada kecepatan dinas, frekuensi natural (yang didapatkan dari pemodelan numerik FEM) agak mendekati frekuensi eksitasi pada mode shape 3. Oleh karena itu, konstuksi pada pondasi 
antara strut dengan linggi buritan perlu diyakinkan penguatannya kearah vertikal.

\section{Saran}

Kondisi resonansi yang ditentukan berdasarkan analisa numerik dapat diuji di lapangan apakah kapal mengalami resonansi atau tidak. Nilai frekuensi alami dari perhitungan dapat berubah-ubah karena kondisi batas yang lebih akurat. Oleh karena itu, perlu dilakukan uji eksperimen sehingga hasil numerik dapat dijadikan acuan untuk perhitungan getaran kapal pada model yang lainnya.

\section{DAFTAR PUSTAKA}

Imron, A. (1994), Catatan Kuliah Getaran Kapal, Jurusan Teknik Perkapalan, Institut Teknologi Sepuluh Nopember, Surabaya.

Han, H., Lee, K., \& Park, L. S. (2015). Estimate of the Fatigue Life of the Propulsion Shaft from Torsional Vibration Measurement and the Linear Damage Summation Law in Ships, Ocean Engineering, Vol. 107, pp. 212-221.

Han, H. S., Lee, K. H., \& Park, S. H. (2016). Parametric Study to Identify the Cause of High Torsional Vibration of the Propulsion Shaft in the Ship, Engineering Failure Analysis, Vol. 59, pp. 334-346.

Hara, T., Furukawa, T., \& Shoda, K. (1995). Vibration Analysis of Main Engine Shaft System by Building Block Approach, Bulletin of the M.E.S.J. 23 (02), Tokyo.

Huang, X., Ni, Z., Zhang, Z., \& Hua, H. (2017), Stiffeness Oprimization of Marine Propulsion Shafting System by FRP-Based Substructing Method and Sensitivity Analysis, Ocean Engineering, Vol. 144, pp. 243-256.

Loccufier, M., Petit, F., \& Aeyels,D. (2007). Feasibility Study of Vibration Absorbers with Simplified Ship Propulsion Models, IFAC Proceedings Volumes, Vol. 40, No. 17, pp. 379-384.

Muscia, R. (2018). Study of a Vibrating Propulsion System for Marine Vessels: Evaluation of the Efficiency for a Boat $13 \mathrm{~m}$ Long, International Journal of Naval Architecture and Ocean Engineernig, Vol. 10, No. 2, pp. 201-211.

Prihatmoko, D., \& Nugroho, T. F. (2013). Analisa Getaran dan Sistem Perporosan Pada Reduction Gear KM. KUMALA. Skripsi, Jurusan Teknik Sistem Perkapalan, Institut Teknologi Sepuluh Nopember, Surabaya.

Putranto, T., \& Sulisetyono, A. (2017). Lift-Drag Coefficient and Form Factor Analyses of Hydrofoil due to The Shape and Angle of Attack, International Journal of Applied Engineering Research, Vol. 12, No. 21, pp. $11152-11156$

Putranto, T., Suastika, K., \& Gunanta, J. (2017). Intact Stability Analysis of Crew Boat with Variation of
Deadrise Angle, IPTEK Journal of Proceedings Series, No. 2, pp. 124-127.

Stapersma, D., \& Vrijdag, A. (2017). Linearisation of a Ship Propulsion System Model, Ocean Engineerng, Vol. 142, pp. 441-457.

Sestan, A., Vladimir, N., Vulic, N., \& Ljubenkov, B. (2012). A Study into Resonant Phenomena in the Catamaran Ferry Propulsion System, Transaction of FAMENA, Vol. 36 (1), pp. 35-44.

Tang, B. (2009). Dynamic Analysis of Crankshafts Using Dynamic Stiffness Matrix, Journal of Ship Mechanics (English Edition), Vol. 13, No. 3, pp. 465-467.

Tang, B., Xue, D. X., \& Song, X. G. (2009). Review of Torsional Vibration Analysis of Multi-Branched Shaft Systems, Noise and Vibration Control, Vol. 29, No. 3, pp. 1-5.

Taskar, B., Yum, K. K., Steen, S., \& Pedersen, E. (2016). The Effect of Wave on Engine-Propeller Dynamics and Propulsion Performance of Ships, Ocean Engineering, Vol. 122, pp. 262-277.

Zhang, S., \& Zhang, Q. (2008). Coupled Torsional and Axial Nonlinear Vibration Model of the Crankshaft with a Propeller, Shanghai, International Conference on System Simulation and Scientific Computing. 
